Meta-Analysis

\title{
Meta-analysis of incidence and risk of severe adverse events and fatal adverse events with crizotinib monotherapy in patients with ALK-positive NSCLC
}

\author{
Qian Zhu ${ }^{1, *}$, Hao Hu ${ }^{2, *}$, Feng Jiang ${ }^{3, *}$, Chang Ying Guo ${ }^{3}$, Xiong Wen Yang ${ }^{4}$, Xi Liu ${ }^{3}$ \\ and Yu Kang Kuang ${ }^{2,3}$ \\ ${ }^{1}$ Department of Biotherapy, Sun Yat-sen University Cancer Center, Guangzhou 510060, Guangdong, China \\ ${ }^{2}$ Department of Thoracic Surgery, Medical College of Nanchang University, Nanchang 330000, Jiangxi, China \\ ${ }^{3}$ Department of Thoracic Surgery, Jiangxi Province Tumor Hospital, Nanchang 330006, Jiangxi, China \\ ${ }^{4}$ Department of Lung Cancer Center, First People's Hospital Chenzhou, Chenzhou 423000, Hunan, China \\ "These authors contributed equally to this work
}

Correspondence to: Yu Kang Kuang, email: kuangyukang1@163.com

Keywords: crizotinib, severe adverse effects, fatal adverse effects, non-small cell lung cancer, anaplastic lymphoma kinase

Received: February 08, 2017

Accepted: June 04, 2017

Published: June 17, 2017

Copyright: Zhu et al. This is an open-access article distributed under the terms of the Creative Commons Attribution License 3.0 (CC BY 3.0), which permits unrestricted use, distribution, and reproduction in any medium, provided the original author and source are credited.

\section{ABSTRACT}

Background: Numerous clinical trials show crizotinib has promising efficacy for anaplastic lymphoma kinase (ALK) positive non-small cell lung cancer (NSCLC) patients which trigger the substitution of traditional chemotherapy to be the current standard first-line treatment for these patients. Conversely, few reports systematically analyze toxicity of crizotinib. Hence, we performed a first meta-analysis to determine the risk of crizotinib-related severe adverse events (SAEs) and fatal adverse events (FAEs) in ALK positive NSCLC patients.

Materials and Methods: A systematic literature search was conducted through December 2016 to identify clinical trials that reported crizotinib monotherapy in ALKpositive NSCLC patients. Data on crizotinib-related SAEs and FAEs were extracted from each study and pooled to determine the overall incidence and risk. Random-effects or fixed-effects models were conducted to calculate the summary incidence, relative risk (RR), and $95 \%$ CIs on basis of the heterogeneity of included studies.

Results: 1,924 patients from 11 clinical trials were included. The overall incidence of SAEs and FAEs with crizotinib was $19.9 \%(95 \%$ CI, $14.1 \%$ to $23.7 \% ; P<0.001$ ) and $1.4 \%(95 \% \mathrm{CI}, 0.9 \%$ to $2.1 \% ; P<0.001)$, respectively. Meanwhile, Asian patients have lower incidence of SAEs $(11.5 \%, 95 \%$ CI: $7.9 \%$ to $16.5 \%)$. However, significant differences of SAEs (RR: $0.97,95 \% \mathrm{CI}, 0.79$ to $1.18 ; P=0.76$ ) and FAEs (RR: 2.24 , $95 \% \mathrm{CI}, 0.49$ to $10.30 ; P=0.30$ ) were not detected between crizotinib monotherapy and chemotherapy.

Conclusions: Crizotinib may not increase the risk of SAEs and FAEs in patients with ALK positive NSCLC compared with chemotherapy.

\section{INTRODUCTION}

Lung cancer is the leading cause of cancer morbidity and mortality in the world [1]. Approximately $85 \%$ of lung cancer cases are characterized as non-small cell lung cancer (NSCLC) cases [2] and anaplastic lymphoma kinase $(A L K)$ positive is therein non-negligible, occurring in 2 to $7 \%$ of all NSCLC [3]. Crizotinib, a multiple smallmolecule inhibitor of ALK, mesenchymal-epithelial transition (MET) and c-ros oncogene 1 (ROS1), was first approved in 2011 by the United States (US) Food and Drug Administration (FDA) for treatment of patients with local advanced or metastatic $A L K$-positive NSCLC based on the results of early phase clinical trials [4]. 
Now, crizotinib has become a recommended standard of care for patients with $A L K$-positive NSCLC according to the National Comprehensive Cancer Network guideline [5]. Meanwhile, it is usually reported that crizotinib is generally well tolerated in patients with $A L K$ positive NSCLC, with most treatment-related adverse events of a grade 2 or less, including gastrointestinal disturbances and visual events [6]. Other toxicities have been reported and mainly include peripheral edema, dizziness, fatigue and decreased appetite [7].

However, the incidence and risk of SAEs and FAEs are frequently overlooked during the treatment decisionmaking process, which have grave consequences to the patient, family and society [8]. Moreover, crizotinibrelated SAEs and FAEs have been noted in clinical practice and clinical trials [9-12]. Unfortunately, few reports systematically analyze severe and fatal toxicity of crizotinib. Hence, we performed this meta-analysis to estimate the incidence and risk of SAEs and FAEs with crizotinib among $A L K$-positive NSCLC patients.

\section{MATERIALS AND METHODS}

\section{Study strategy}

In December 2016, we performed an electronic search of the Web of Science, EMBASE, PubMed, and Cochrane Library databases. Meanwhile, we searched abstracts presented at major meetings from the American Society of Clinical Oncology (ASCO), the European Society for Medical Oncology (ESMO) and the World Lung Cancer Conference (WCLC). An independent search of relevant reviews and meta-analyses associated with crizotinib was also done to ensure no studies were missed. The following key word was used: crizotinib. We limited language to English, but the publication years were not limited. Finally, reference lists of original papers and review papers were also scanned. We contacted the corresponding authors of some studies for further information if necessary. Our study was managed based on the Preferred Reporting Items for Systematic Reviews and Meta-analyses (PRISMA) guidelines [13].

\section{Study selection}

The inclusion criteria were as follows: (a) crizotinib monotherapy in clinical trials; (b) treatment-related SAEs (grade 3/4) and FAEs (grade 5) were reported; (c) pathologic confirmation of $A L K$-positive NSCLC; and (d) publication language is English. If the articles were based on the same trial, the latest and the most complete data only were used for this analysis. Two investigators evaluated the articles for relevance independently.

\section{Exclusion criteria}

Reviews, editorials, case reports were excluded. The aim of our study was to investigate incidence and risk of crizotinib monotherapy among adult patients with $A L K$ positive NSCLC. We thus excluded studies involving pediatric patients, patients without $A L K$ positive NSCLC, trials that combination with crizotinib and other therapy in the intervention and/or control cohorts.

\section{Study quality assessment}

Two investigators (Q. Zhu and H. Hu) independently assessed risk of bias in randomized control trials (RCTs) using the Cochrane collaboration's tool for assessing risk of bias [14]. Two investigators independently assessed each study under five main headings for risk of bias. Similarly, two investigators (F. Jiang and C Y. Guo) assessed the full texts of non-randomized clinical trials (NRCTs) using the 9-point Newcastle Ottawa scale (NOS) [15]. Each study was independently evaluated by two investigators based on eight items, categorized into three broad perspectives including selection, comparability and outcome for cohort studies or exposure for casecontrol studies. Studies with a score of 7 or greater were considered as high quality. Disagreements were resolved by discussion or through consultation with the senior reviewer.

\section{Data extraction}

All articles were first catalogued (article title, author names and year of publication) before selection. The abstracts of the articles were evaluated independently by two investigators (X W. Yang and X. Liu). Outcomes were pooled for the occurrence of crizotinib-related SAEs and/ or FAEs. Data were pooled and transferred into a standard electronic form. Discrepancies, when identified, were solved by discussion until a consensus was reached. Any final decision regarding the eligibility of a study and data were extracted by the principal investigator (Y K. Kuang).

\section{Clinical endpoints and statistical analysis}

All statistical analysis was performed with Comprehensive Meta-analysis software, version 3 (Biostat, Englewood, USA). SAEs and FAEs, extracted from the safety profile in each trial with crizotinib monotherapy in $A L K$-positive NSCLC, were applied to clinical end points and noted according to version 3 or 4 of the Common Terminology Criteria for Adverse Events (CTCAE). Data on the number of patients with SAEs and FAEs, as well as the number of patients receiving crizotinib were extracted from the publications of the selected studies for the calculation of incidence and the proportion of patients 
with SAEs and FAEs and 95\% confidence intervals (CIs) were deduced for each study. A classic half-integer continuity correction for the calculation of incidence and relative risk (RR) was used while zero events were reported in the crizotinib or control cohort. To compare adverse effect rates of crizotinib with control regimens, the RR was calculated. The pooled estimate for incidence and RRs were assessed with random-effects or fixed-effects model based on the heterogeneity of included studies. Assumption of homogeneity for the Cochrane Q statistic with values of $P<0.10$ was considered to be invalid. Cochran's Q test was used to assess between-study differences and the inconsistency was quantified with the $\mathrm{I}^{2}$ statistic. When the heterogeneity was in-existent, fixedeffects model was used to pool the summary incidence and RRs otherwise random effects model was used.

To explore the possible reasons for any observed heterogeneity, we performed the following pre-specified subgroup analyses and meta-regression: study design (prospective versus retrospective), ethnicity (Asian versus Multi-race) and percentage of Asian patients. We tried to limit the number of subgroup analyses with suggestion in the Cochrane Handbook and no post-hoc subgroup analyses were performed [16]. Also, subgroup analyses were not conducted while heterogeneity was nonexistent. Begg's [17] and Egger's tests [18] along with the funnel plots were assessed publication bias for both SAEs and FAEs. All tests were two-tailed and $P<0.05$ was considered as statistical significance.

\section{RESULTS}

\section{Trial flow and study characteristics}

Our literature search yielded a total of 4523 articles on crizotinib. After evaluating each publication, we identified 27 studies for eligibility. After further evaluation, sixteen studies were excluded (four studies: inadequate data on severe AEs, four studies: not the latest article with the most complete data, eight studies: not reported data of SAEs and FAEs). The rest eleven studies met our inclusion criteria [6, 12, 19-27] (Figure 1). Five studies $[6,12,20-22]$ were prospective and six studies $[19,23-27]$ were retrospective. A total of 1,924 patients
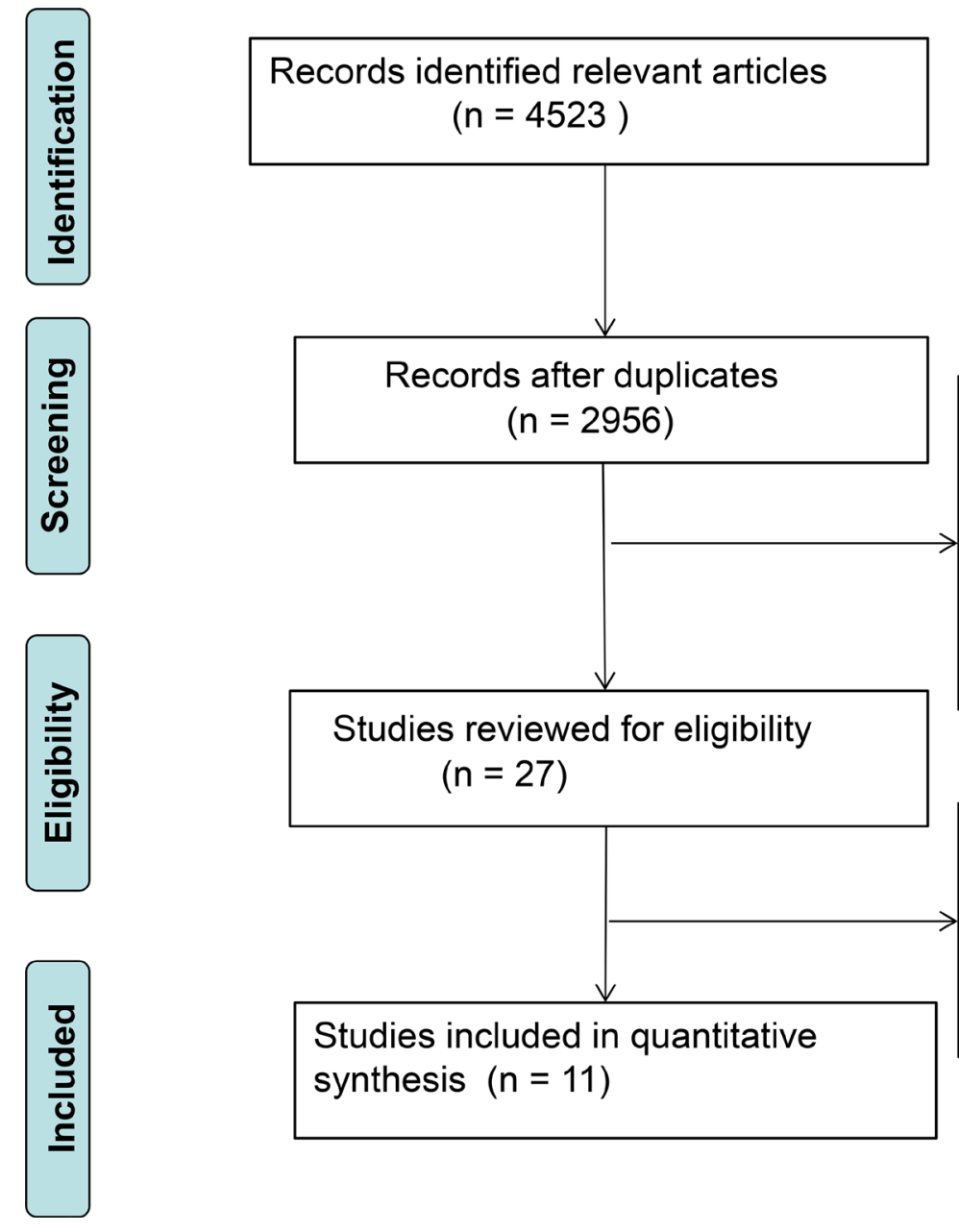

Records excluded $(n=2929)$
566 Reviews or case reports
283 Editorials or commentaries
1229 Not clinical trials
253 Not adult with ALK+ NSCLC
213 Not in English
385 Not crizotinib monotherapy

Records excluded $(n=16)$ 4 Inadequate data on SAEs 4 Not the latest article with the most complete data 8 Not reported data of SAEs

Figure 1: The flow diagram of meta-analysis. $A L K$, anaplastic lymphoma kinase; NSCLC, non-small cell lung cancer; SAEs, severe adverse events. 
were available for the meta-analysis. All the patients tend to be younger (median age: 42-57), adenocarcinoma (94\%-100\%) and advanced stage (stage III and/or IV). All the initial crizotinib dose and schedule of dosage was based on the US FDA guidelines $(250 \mathrm{mg}$, orally, twice a day) and at least one dose of the treatment was utilized. The baseline characteristics of all studies were listed in Table 1.

\section{Study quality assessment and risk of bias}

No major flaw was observed in assessment of risk of bias in RCTs. However, a common flaw was the absence of expected blinded intervention (more details were summarized in the Supplementary Table 1). We summarized the methodological quality of all the NRCTs (excluding PROFILE 1005 trial) in the Supplementary Table 2. The NOS results showed that the average overall score was 6.75 (range 6-9).

\section{Incidence of SAEs}

For the incidence of SAEs, all studies were included, representing a total of 1,924 patients. By using a random effects model (heterogeneity test: $\mathrm{Q}=79.01 ; \mathrm{I}^{2}=87.34 \%$; $P<0.001)$, the incidence of crizotinib-related SAEs was determined to be $19.9 \%$ (95\% CI, $14.1 \%$ to $23.7 \%$, $P<0.001$; Figure 2). The incidence of SAEs was highest in the PROFILE 1005 trial [22] (39.9\%; 95\% CI, 37.0\% to $42.8 \%$ ) and lowest in the Wang study [23] (5.7\%; $95 \% \mathrm{CI}, 1.8 \%$ to $16.1 \%)$. The incidence of SAEs varied significantly with study design $(P<0.001)$ and ethnicity $(P<0.001)$. The summary incidence rates were 30\% $(95 \%$ CI, $23.2 \%$ to $37.8 \%$ ) for prospective study and $10.5 \%(95 \%$ CI, $6.4 \%$ to $16.8 \%$ ) for retrospective study, respectively. Notably, the summary incidence rate was lower in Asian patients $(11.5 \%, 95 \% \mathrm{CI}: 7.9 \%$ to $16.5 \%)$ (Table 2$)$. To further analyze the causes of heterogeneity, we performed meta-regression. There was significant correlation between the proportion of Asian patients and the incidence of SAEs $(P<0.001)$. Hence, the proportion of Asian patients can partly explain the heterogeneity between the trials.

No evidence of publication bias was detected for incidence of SAEs by the Begg's $(P=0.12)$ but the Egger's test $(P<0.001)$.

\section{Incidence of FAEs}

For the incidence of FAEs, all these studies were included, representing a total of 1,924 patients. By using a fixed effects model (heterogeneity test: $\mathrm{Q}=3.79 ; \mathrm{I}^{2}=$ $0 \% ; P=0.956)$, the incidence of FAEs due to crizotinib

\section{Incidence of severe adverse events}

\section{Model Study name}

D Ross Camidge (2012)

Alice T. Shaw (2013)

Benjamin J. Solomon (2014)

Yabing, Cao (2014)

Shaohua,Cui (2015)

PROFILE1005 (2015)

Yan, Wang (2015)

Shaohua, Cui (2016)

Quan, Zhang (2016)

Tatsuya Yoshida (2016)

Puyuan Xing (2016)

Random
Statistics for each study

$\begin{array}{cccr}\begin{array}{c}\text { Lower } \\ \text { limit }\end{array} & \begin{array}{c}\text { Event } \\ \text { rate }\end{array} & \begin{array}{c}\text { Upper } \\ \text { limit }\end{array} & \text { p-Value } \\ 0.180 & 0.242 & 0.317 & 0.000 \\ 0.265 & 0.331 & 0.405 & 0.000 \\ 0.283 & 0.351 & 0.425 & 0.000 \\ 0.069 & 0.150 & 0.296 & 0.000 \\ 0.076 & 0.139 & 0.239 & 0.000 \\ 0.370 & 0.399 & 0.428 & 0.000 \\ 0.018 & 0.057 & 0.161 & 0.000 \\ 0.073 & 0.143 & 0.261 & 0.000 \\ 0.020 & 0.143 & 0.581 & 0.097 \\ 0.028 & 0.086 & 0.234 & 0.000 \\ 0.015 & 0.059 & 0.207 & 0.000 \\ 0.141 & 0.199 & 0.273 & 0.000\end{array}$

\section{Event rate and $95 \% \mathrm{Cl}$}

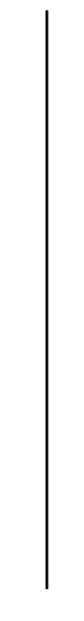

$-0.50$
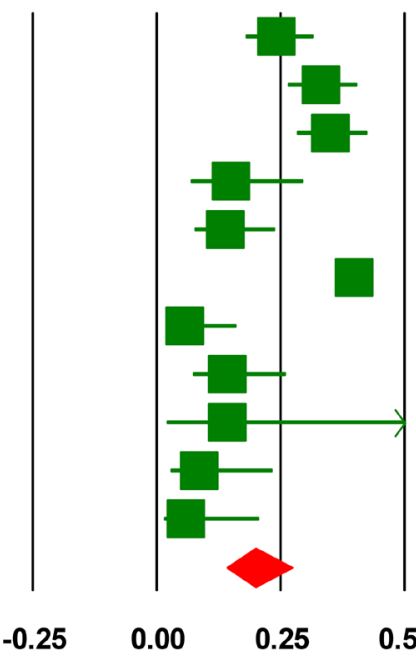

Figure 2: Forest-plot of the overall incidence of crizotinib-related severe adverse events. 
Table 1: Primary characteristics of the selected studies

\begin{tabular}{|c|c|c|c|c|c|c|c|c|c|c|c|}
\hline Study (Reference) & Year & $\begin{array}{c}\text { Numbers } \\
\text { (Safety) }\end{array}$ & $\begin{array}{c}\text { Age } \\
\text { (Median) }\end{array}$ & Ethnicity & A (\%) & SAEs & FAEs & Line of therapy & $\begin{array}{l}\text { Study } \\
\text { design }\end{array}$ & $\begin{aligned} & \text { PS } \geq 2 \\
&(\%)\end{aligned}$ & $\begin{array}{l}\text { Clinical } \\
\text { stage }\end{array}$ \\
\hline D Ross Camidge [6] & 2012 & 149 & $52 \mathrm{Y}$ & Multi-race & $97 \%$ & 36 & 0 & Mixed-line & prospective & $12 \%$ & Stage III /IV \\
\hline Alice T. Shaw [12] & 2013 & 172 & $51 \mathrm{Y}$ & Multi-race & $95 \%$ & 57 & 3 & Second-line & prospective & $9 \%$ & Stage III /IV \\
\hline Yabing, Cao [19] & 2014 & 40 & $42 \mathrm{Y}$ & Asian & $100 \%$ & 6 & 0 & Mixed-line & retrospective & NA & Stage III /IV \\
\hline $\begin{array}{l}\text { Benjamin J. Solomon } \\
{[20]}\end{array}$ & 2014 & 171 & $52 \mathrm{Y}$ & Multi-race & $94 \%$ & 60 & 0 & First-line & prospective & $6 \%$ & Stage III /IV \\
\hline Shaohua,Cui [21] & 2015 & 72 & $55 \mathrm{Y}$ & Asian & $94.4 \%$ & 10 & 1 & Mixed-line & prospective & $2.8 \%$ & Stage III /IV \\
\hline PROFILE1005 [22] & 2015 & 1066 & $52.2 \mathrm{Y}$ & Multi-race & $95 \%$ & 425 & 15 & Mixed-line & prospective & NA & Stage III /IV \\
\hline Yan, Wang [23] & 2015 & 53 & $50 \mathrm{Y}$ & Asian & $98 \%$ & 3 & 0 & Mixed-line & retrospective & $21 \%$ & Stage III /IV \\
\hline Shaohua, Cui [24] & 2016 & 56 & $55 \mathrm{Y}$ & Asian & $100 \%$ & 8 & 1 & Mixed-line & retrospective & $2 \%$ & Stage III /IV \\
\hline Puyuan Xing [25] & 2016 & 34 & $51.5 \mathrm{Y}$ & Asian & NA & 2 & 0 & Mixed-line & retrospective & $2.9 \%$ & Stage IV \\
\hline Tatsuya Yoshida [26] & 2016 & 35 & $57 \mathrm{Y}$ & Asian & $100 \%$ & 3 & 0 & Mixed-line & retrospective & $14 \%$ & Stage III /IV \\
\hline Quan, Zhang [27] & 2016 & 7 & $53 \mathrm{Y}$ & Asian & $100 \%$ & 1 & 0 & First-line & retrospective & $0 \%$ & Stage IV \\
\hline
\end{tabular}

Y: years; A: Adenocarcinoma; SAEs: Severe adverse events. FAEs: Fatal adverse events. NA: Not available. PS: Performance Status.

was determined to be $1.4 \%$ ( $95 \% \mathrm{CI}, 0.9 \%$ to $2.1 \%$, $P<0.001$; Figure 3). The incidence of FAEs was highest in the Zhang study [27] (6.7\%) and lowest in the Camidge study [6] and Solomon study [20] (0.3\%). No FAEs were observed in seven trials $[6,19,20,23,25-27]$. Because heterogeneity was not observed, subgroup analyses were not done for FAEs. To account for any possible clinical heterogeneity not detected by statistical tests, randomeffects model was also used to pool the data: the incidence and $95 \% \mathrm{CI}$ remained unchanged.

\section{Incidence of fatal adverse events}

\section{Model Study name}

D Ross Camidge (2012)

Alice T. Shaw (2013)

Benjamin J. Solomon (2014)

Yabing, Cao (2014)

Shaohua,Cui (2015)

PROFILE1005 (2015)

Yan, Wang (2015)

Shaohua, Cui (2016)

Quan, Zhang (2016)

Tatsuya Yoshida (2016)

Puyuan Xing (2016)

Fixed
Statistics for each study

$\begin{array}{cccr}\begin{array}{c}\text { Lower } \\ \text { limit }\end{array} & \begin{array}{c}\text { Event } \\ \text { rate }\end{array} & \begin{array}{c}\text { Upper } \\ \text { limit }\end{array} & p \text {-Value } \\ 0.000 & 0.003 & 0.051 & 0.000 \\ 0.006 & 0.017 & 0.053 & 0.000 \\ 0.000 & 0.003 & 0.045 & 0.000 \\ 0.001 & 0.012 & 0.169 & 0.002 \\ 0.002 & 0.014 & 0.092 & 0.000 \\ 0.009 & 0.014 & 0.023 & 0.000 \\ 0.001 & 0.009 & 0.133 & 0.001 \\ 0.003 & 0.018 & 0.116 & 0.000 \\ 0.004 & 0.067 & 0.557 & 0.071 \\ 0.001 & 0.014 & 0.189 & 0.003 \\ 0.001 & 0.014 & 0.194 & 0.003 \\ 0.009 & 0.014 & 0.021 & 0.000\end{array}$

Event rate and $95 \% \mathrm{Cl}$

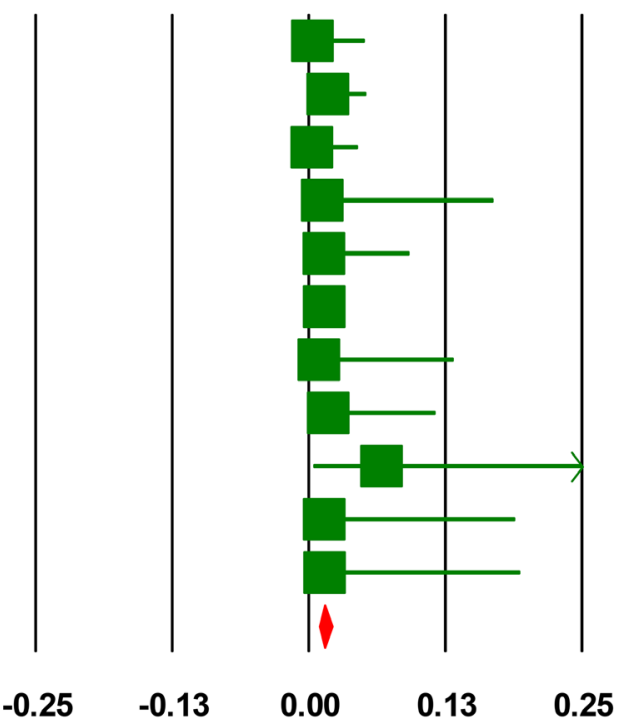

Figure 3: Forest-plot of the overall incidence of crizotinib-related fatal adverse events. 
Table 2: Heterogeneity in the incidence of crizotinib-related severe adverse events

\begin{tabular}{lllll}
\hline & & Incidence & 95\% CI & $\begin{array}{c}P \text {-value for } \\
\text { heterogeneity test }\end{array}$ \\
\hline \multirow{2}{*}{ Study design } & prospective study & $30 \%$ & $23.2 \%-37.8 \%$ & \\
& retrospective study & $10.50 \%$ & $6.4 \%-16.8 \%$ & $P<0.001$ \\
Ethnicity & Asian & $11.50 \%$ & $7.95-16.5 \%$ & $P<0.001$ \\
\hline
\end{tabular}

No evidence of publication bias was detected for incidence of SAEs by either the Begg's $(P=0.75)$ or the Egger's test $(P=0.60)$.

\section{RR of SAEs and FAEs}

Four studies comparing crizotinib with chemotherapy were included to provide the RR of toxicity profile results. In the crizotinib group, all the initial crizotinib dose and schedule of dosage was $250 \mathrm{mg}$, orally, twice a day. In the chemotherapy group, platinumbased double-agent chemotherapy was used in all included studies except one study [12] with single-agent chemotherapy. The overall incidence of chemotherapyrelated SAEs was determined to be $26.5 \%$ (95\% CI, $16.6 \%$ to $39.4 \%, P=0.001$; Supplementary Figure 1 ).

The summary RR of developing a crizotinib-related SAEs was 0.97 ( $95 \%$ CI, 0.79 to $1.18, P=0.76$; Figure 4). This estimate was acquired by using fixed-effects model because no significant heterogeneity was detected $\left(\mathrm{Q}=0.98, P=0.81, \mathrm{I}^{2}=0.0 \%\right)$ and therefore subgroup analyses were not done. To account for any possible clinical heterogeneity not detected by statistical tests, we also pooled the data using random-effects model: the RR and $95 \% \mathrm{CI}$ remained unchanged.

The summary RR of developing a crizotinibrelated FAEs was 2.24 ( $95 \% \mathrm{CI}, 0.49$ to $10.30, P=0.30$; Figure 5). This estimate was also acquired by using fixedeffects model because no significant heterogeneity was detected $\left(\mathrm{Q}=0.27, P=0.97, \mathrm{I}^{2}=0.0 \%\right)$ and therefore subgroup analyses were also not done. To account for any possible clinical heterogeneity not detected by statistical tests, we also pooled the data using random-effects model: the $\mathrm{RR}$ and $95 \% \mathrm{CI}$ remained unchanged.

\section{DISCUSSION}

Crizotinib has been the current standard first-line treatment for $A L K$ positive NSCLC patients based on the result of the prospectively randomized PROFILE 1014 trial [20]. Although efficacy was quite important in clinical practice and clinical trials, safety profile was also notable.

\section{RR of SAEs with Crizotinib}

Model Study name

Alice T. Shaw (2013)
Benjamin J. Solomon (2014)
Shaohua Cui (2016)
Quan Zhang (2016)

Fixed

\section{Statistics for each study}

Risk Lower Upper

ratio limit limit $p$-Value

$\begin{array}{llll}1.03 & 0.76 & 1.40 & 0.85 \\ 0.90 & 0.68 & 1.19 & 0.45 \\ 1.43 & 0.50 & 4.08 & 0.51 \\ 0.86 & 0.09 & 7.83 & 0.89 \\ 0.97 & 0.79 & 1.18 & 0.76\end{array}$

Risk ratio and $95 \% \mathrm{Cl}$

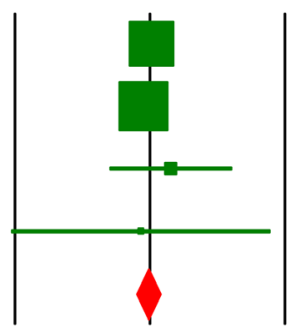

$\begin{array}{lll}0.1 & 1 & 10\end{array}$

100

Favours Crizotinib Favours Chemotherapy

Figure 4: Forest-plot of the relative risk of severe adverse events (SAEs) associated with crizotinib versus chemotherapy. 
Up to now, this is the first and largest study to determine incidence and risk of crizotinib-related SAEs and FAEs in $A L K$ positive NSCLC patients. The crude overall incidence of crizotinib-related SAEs and FAEs was 19.9\% and $1.4 \%$, respectively. Meantime, crizotinib use may not increase the risk of both SAEs (RR: 0.97, $P=0.76$ ) and FAEs (RR: $2.24, P=0.30$ ) compared to chemotherapy. Of note, the risk of developing an FAE was more than twofold higher in patients treated with crizotinib compared with patients treated in chemotherapy arms. However, no statistically significant difference was detected and the difference between two groups was probably affected by the fact that the duration of treatment in the crizotinib group was longer than those in the chemotherapy group and that more patients in the crizotinib group continued treatment beyond progression $[12,28]$. Moreover, the occasional wide variation in the confidence interval of the risk was observed and may be ascribed to the limited small number of trials. Hence, the current findings did not produce adequate power to detect potentially relevant differences in FAEs between the two strategies.

It is noteworthy that severe adverse events (grade 3 or 4) defined are different with the definitions of serious adverse events, although the abbreviation was the same as "SAEs". A serious adverse event was defined as follows: death; life-threatening; hospitalization or prolongation of existing hospitalization; results in persistent or significant disability/incapacity and so on [20]. Nonetheless, according to CTCAE, version 4.0, grade 3 and 4 were defined as "severe or medically significant but not immediately life-threatening; hospitalization or prolongation of hospitalization; disabling; limiting activities of daily living" and "life-threatening consequences", respectively. Thus, it is different between severe adverse events and serious adverse events. For instance, the incidence of treatment-related serious adverse events in the PROFILE 1014 trial was $10.5 \%$ [29]. However, crizotinib-related SAEs in the PROFILE 1014 trial were mostly elevated aminotransferases (14\%) and neutropenia (11\%) [20]. These toxicities might be managed with dose interruptions or dose reductions and without life-threatening conditions or hospitalization [20].

Although the actual incidence of FAEs was relatively low at $1.4 \%$, SAEs developed in as many as almost one-fifth of all patients receiving crizotinib. Treating cancer with modern targeted therapies is a double edged sword. Patients frequently incline to overestimate the benefit of treatment and underestimate the harms [30]. Therefore, the discussion of the adverse effects (especially for SAEs) between clinicians and patients prior to treatment was necessary in routine clinical practice. Without understanding of these adverse events properly, patients and clinicians will unable to proper judge the risk-benefit balance [8]. Hence, it is worth to notice these toxicity profiles in routine clinical practice and clinical trials.

It is remarkable that the incidence of crizotinibrelated SAEs in Asian patients was lower (11.5\%). It is consistent with the previous report, which estimated the differences in crizotinib pharmacokinetics between Asian and non-Asian patients, that Asian patients have lower incidence of SAEs [31]. However, it should be pointed out

\section{RR of FAEs with Crizotinib}

\section{Model Study name}

Alice T. Shaw (2013)

Benjamin J. Solomon (2014)

Shaohua Cui (2016)

Quan Zhang (2016)

Fixed

\section{Statistics for each study}

Risk Lower Upper ratio limit limit $p$-Value

$\begin{array}{llll}2.98 & 0.31 & 28.39 & 0.34\end{array}$

$\begin{array}{llll}0.99 & 0.02 & 49.52 & 1.00\end{array}$

$\begin{array}{llll}2.68 & 0.11 & 64.35 & 0.54\end{array}$

$\begin{array}{llll}1.67 & 0.04 & 75.55 & 0.79\end{array}$

$\begin{array}{llll}2.24 & 0.49 & 10.30 & 0.30\end{array}$

\section{Risk ratio and $95 \% \mathrm{Cl}$}

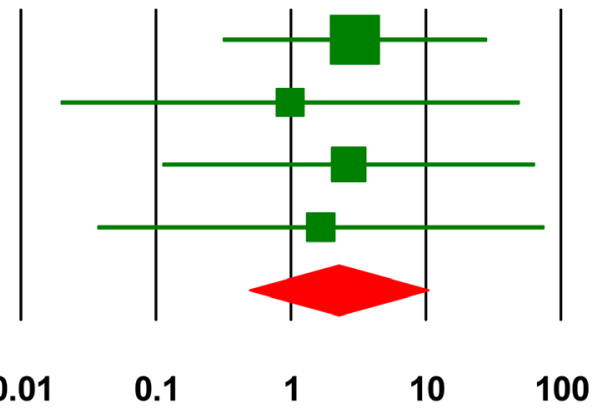

Favours Crizotinib Favours Chemotherapy

Figure 5: Forest-plot of the relative risk of fatal adverse events (FAEs) associated with crizotinib versus chemotherapy. 
that all studies with only Asian patients included in our meta-analysis were retrospective. Moreover, as shown in Table 2, significant differences of incidence of SAEs were observed between prospective and retrospective studies in the exploratory subgroup analysis. Meanwhile, as shown in Supplementary Table 3, there were some differences in the safety assessment between prospective and retrospective studies. What is more, it was not reported that how an adverse event was assessed and what factors (physical examintation, documentation of adverse events or laboratory test) were included in most retrospective studies. Hence, bias and confounding in retrospective studies (for instance, lack of management of toxicity, selection bias) may bias the finding. Even so, random-effects model was used in the analysis of incidence of SAEs.

The ALK expresses in many tissues including eye, olfactory nerve, skins, tissue surrounding the esophagus, stomach and midgut [32]. Therefore, on-target anti-ALK effects in normal tissue play an important role in inducing side-effects during the treatment [6]. However, crizotinib is also a MET and ROS1 inhibitor. Thus, whether antiMET effects, anti-ROS1 effects or other specific effects could also be contributing to these adverse events is still unclear.

Interestingly, with an increasing number of patients being treated with crizotinib, new and more adverse effects of crizotinib are coming to light such as hormonal and electrolyte abnormalities, grade IV hypersensitivity rashes [33]. Notably, crizotinib is a multiple smallmolecule inhibitor of ALK, MET and ROS1. Liu et al. [34] suggested that the peripheral edema was more common in c-MET inhibition compared to crizotinib. As what mentioned before, this adverse event was observed significantly less in a Phase I study of ceritinib, as well as alectinib, which more specifically inhibits ALK without inhibition of c-MET [33]. Hence, it seems reasonable to hypothesize that more specific inhibitors, focused solely on the ALK tyrosine kinase, bring patients less toxicity with higher quality of life.

There have several potential limitations to this analysis. One obvious limitation is the tag of these adverse events as treatment-related or disease-related by the study investigator could lead to bias since SAEs and FAEs were not the primary endpoint of any of the trials included in this meta-analysis. Further, other limitations were that the unavailability of details of SAEs data from Noronha study [35] as well as the detection of publication bias in the meta-analysis of SAEs.

\section{CONCLUSIONS}

Crizotinib may not increase the risk of SAEs and FAEs in $A L K$ positive NSCLC patients compared with chemotherapy. Although generally tolerated, appropriate care should be provided in order to minimize its toxicity and the dose needs to be adjusted in case of necessary.

\section{ACKNOWLEDGMENTS}

All authors read and approved the final manuscript.

\section{CONFLICTS OF INTEREST}

The authors have declared no conflicts of interest.

\section{FUNDING}

The present study was supported by the Jiangxi Province's Program of the Preponderant Team Building in Science and Technology Innovation (NO. 20161BCB24011).

\section{REFERENCES}

1. Siegel RL, Miller KD, Jemal A. Cancer statistics, 2015. CA Cancer J Clin. 2015; 65:5-29.

2. Wood SL, Pernemalm M, Crosbie PA, Whetton AD. Molecular histology of lung cancer: from targets to treatments. Cancer Treat Rev. 2015; 41:361-75.

3. Kwak EL, Bang YJ, Camidge DR, Shaw AT, Solomon B, Maki RG, Ou SH, Dezube BJ, Jänne PA, Costa DB, VarellaGarcia M, Kim WH, Lynch TJ, et al. Anaplastic lymphoma kinase inhibition in non-small-cell lung cancer. N Engl J Med. 2010; 363:1693-703.

4. Elliott WT, James C. Crizotinib Capsules (Xalkori). Internal Medicine Alert. 2011; 33:142-43.

5. https://www.ncen.org/patients/guidelines/lung-nsclc/index. html\#88.

6. Camidge DR, Bang YJ, Kwak EL, Iafrate AJ, VarellaGarcia M, Fox SB, Riely GJ, Solomon B, Ou SH, Kim DW, Salgia R, Fidias P, Engelman JA, et al. Activity and safety of crizotinib in patients with ALK-positive non-small-cell lung cancer: updated results from a phase 1 study. Lancet Oncol. 2012; 13:1011-19.

7. Rothschild SI, Gautschi O. Crizotinib in the treatment of non-small-cell lung cancer. Clin Lung Cancer. 2013; $14: 473-80$.

8. Gyawali B, Shimokata T, Ando M, Honda K, Ando Y. Risk of serious adverse events and fatal adverse events with sorafenib in patients with solid cancer: a meta-analysis of phase 3 randomized controlled trialsdagger. Ann Oncol. 2017; 28:246-53.

9. Sawamura S, Kajihara I, Ichihara A, Fukushima S, Jinnin M, Yamaguchi E, Kohrogi H, Ihn H. Crizotinib-associated erythema multiforme in a lung cancer patient. Drug Discov Ther. 2015; 9:142-43.

10. van Geel RM, Hendrikx JJ, Vahl JE, van Leerdam ME, van den Broek D, Huitema AD, Beijnen JH, Schellens JH, Burgers SA. Crizotinib-induced fatal fulminant liver failure. Lung Cancer. 2016; 93:17-19.

11. Conduit C, Wilson M, Hunter K, Murdolo V, Nott L. Severe contact esophagitis in a patient taking crizotinib: A case report. Asia Pac J Clin Oncol. 2015; 11:187-89. 
12. Shaw AT, Kim DW, Nakagawa K, Seto T, Crinó L, Ahn MJ, De Pas T, Besse B, Solomon BJ, Blackhall F, Wu YL, Thomas M, O'Byrne KJ, et al. Crizotinib versus chemotherapy in advanced ALK-positive lung cancer. N Engl J Med. 2013; 368:2385-94.

13. Liberati A, Altman DG, Tetzlaff J, Mulrow C, Gøtzsche PC, Ioannidis JP, Clarke M, Devereaux PJ, Kleijnen J, Moher D. The PRISMA statement for reporting systematic reviews and meta-analyses of studies that evaluate health care interventions: explanation and elaboration. Ann Intern Med. 2009; 151:W65-94.

14. Higgins JP, Altman DG, Gøtzsche PC, Jüni P, Moher D, Oxman AD, Savovic J, Schulz KF, Weeks L, Sterne JA, and Cochrane Bias Methods Group, and Cochrane Statistical Methods Group. The Cochrane Collaboration's tool for assessing risk of bias in randomised trials. BMJ. 2011; 343:d5928.

15. Wells G, Shea B, O'Connell D, Peterson J, Welch V, Losos M, Tugwell P. The Newcastle-Ottawa Scale (NOS) for assessing the quality of nonrandomised studies in meta-analyses. http:// www.ohri.ca/programs/clinical_epidemiology/oxford.asp

16. Cochrane Consumers and Communication Review Group. Heterogeneity and subgroup analyses in Cochrane Consumers and Communication Review Group reviews: planning the analysis at protocol stage. 2014. https://pdfs. semanticscholar.org/baf4/9a097ad9e0ba7534416ebe6ae66 75effa8c2.pdf?_ga=2.93475293.1115090347.15052676412140799628.1505267641

17. Begg CB, Mazumdar M. Operating characteristics of a rank correlation test for publication bias. Biometrics. 1994; 50:1088-101.

18. Egger M, Davey Smith G, Schneider M, Minder C. Bias in meta-analysis detected by a simple, graphical test. BMJ. 1997; 315:629-34.

19. Cao Y, Xiao G, Qiu X, Ye S, Lin T. Efficacy and safety of crizotinib among Chinese EML4-ALK-positive, advancedstage non-small cell lung cancer patients. PLoS One. 2014; 9:e114008.

20. Solomon BJ, Mok T, Kim DW, Wu YL, Nakagawa K, Mekhail T, Felip E, Cappuzzo F, Paolini J, Usari T, Iyer S, Reisman A, Wilner KD, et al, and PROFILE 1014 Investigators. First-line crizotinib versus chemotherapy in ALK-positive lung cancer. N Engl J Med. 2014; 371:2167-77.

21. Cui S, Zhao Y, Gu A, Ge X, Song Y, Zhang W, Lou Y, Dong L, Han B, Jiang L. Efficacy and tolerability of crizotinib in the treatment of ALK-positive, advanced non-small cell lung cancer in Chinese patients. Med Oncol. 2015; 32:626.

22. Phase 2, Open-Label Single Arm Study Of The Efficacy And Safety Of PF-02341066 In Patients With Advanced Non-Small Cell Lung Cancer (NSCLC) Harboring A Translocation Or Inversion Involving The Anaplastic Lymphoma Kinase (ALK) Gene Locus (NCT00932451). http://adisinsight.springer.com/trials/700046767.

23. Wang Y, Zhang J, Gao G, Li X, Zhao C, He Y, Su C, Zhang S, Chen X, Zhang J, Li W, Li B, Zhao J, et al. EML4-ALK Fusion Detected by RT-PCR Confers Similar Response to
Crizotinib as Detected by FISH in Patients with Advanced Non-Small-Cell Lung Cancer. J Thorac Oncol. 2015; 10:1546-52.

24. Cui S, Zhao Y, Dong L, Gu A, Xiong L, Qian J, Zhang W, Niu Y, Pan F, Jiang L. Is there a progression-free survival benefit of first-line crizotinib versus standard chemotherapy and second-line crizotinib in ALK-positive advanced lung adenocarcinoma? A retrospective study of Chinese patients. Cancer Med. 2016; 5:1013-21.

25. Xing P, Wang S, Hao X, Zhang T, Li J. Clinical data from the real world: efficacy of Crizotinib in Chinese patients with advanced ALK-rearranged non-small cell lung cancer and brain metastases. Oncotarget. 2016; 7:84666-74. https://doi.org/10.18632/oncotarget.13179.

26. Yoshida T, Oya Y, Tanaka K, Shimizu J, Horio Y, Kuroda H, Sakao Y, Hida T, Yatabe Y. Differential Crizotinib Response Duration Among ALK Fusion Variants in ALK-Positive NonSmall-Cell Lung Cancer. J Clin Oncol. 2016; 34:3383-89.

27. Zhang Q, Qin N, Wang J, Lv J, Yang X, Li X, Nong J, Zhang $\mathrm{H}$, Zhang X, Wu Y, Zhang S. Crizotinib versus platinum-based double-agent chemotherapy as the first line treatment in advanced anaplastic lymphoma kinase-positive lung adenocarcinoma. Thorac Cancer. 2016; 7:3-8.

28. Shaw AT, Solomon BJ, Mok T, Kim DW, Wilner KD, Selaru P, Polli A. Effect of treatment duration on incidence of adverse events (AEs) in a phase III study of crizotinib versus chemotherapy in advanced ALK-positive non-small cell lung cancer (NSCLC). J Thorac Oncol. 2013; 8:S911-12.

29. https://clinicaltrials.gov/ct2/show/NCT01154140?term $=P R$ OFILE+1014\&rank=1.

30. Hoffmann TC, Del Mar C. Patients' expectations of the benefits and harms of treatments, screening, and tests: a systematic review. JAMA Intern Med. 2015; 175:274-86.

31. Ou SH, Salgia R, Clark J, Kwak EL, Camidge DR, Maki R, Bang YJ, Solomon B, Tan WW, Shapiro GI. Comparison of Crizotimb (PF-02341066) pharmacokinetics between asian and non-asian patients with advanced malignancies. J Thorac Oncol. 2010; 5:S382-382.

32. Vernersson E, Khoo NK, Henriksson ML, Roos G, Palmer RH, Hallberg B. Characterization of the expression of the ALK receptor tyrosine kinase in mice. Gene Expr Patterns. 2006; 6:448-61.

33. Dikopf A, Wood K, Salgia R. A safety assessment of crizotinib in the treatment of ALK-positive NSCLC patients. Expert Opin Drug Saf. 2015; 14:485-93.

34. Liu CN, Mathialagan N, Lappin P, Fortner J, Somps C, Seitis G, Johnson TR, Hu W, Matsumoto D. Crizotinib reduces the rate of dark adaptation in the rat retina independent of ALK inhibition. Toxicol Sci. 2015; 143:116-25.

35. Noronha V, Ramaswamy A, Patil VM, Joshi A, Chougule A, Kane S, Kumar R, Sahu A, Doshi V, Nayak L, Mahajan A, Janu A, Prabhash K. ALK Positive Lung Cancer: Clinical Profile, Practice and Outcomes in a Developing Country. PLoS One. 2016; 11:e160752. 